\title{
Analysis and Design of Coupled Inductors for Two-Phase Interleaved DC-DC Converters
}

\author{
Jong-Pil Lee ${ }^{*}$, Honnyong Cha ${ }^{\dagger}$, Dongsul Shin ${ }^{* *}$, Kyoung-Jun Lee ${ }^{* *}$, \\ Dong-Wook Yoo ${ }^{*}$, and Ji-Yoon Yoo ${ }^{* *}$ \\ *Power Conversion \& Control Research Center, KERI, Changwon, Korea \\ ${ }^{\dagger}$ School of Energy Eng., Kyungpook National University, Deagu, Korea \\ ${ }^{* *}$ Dept. of Electrical Eng., Pusan National University, Busan, Korea \\ ${ }^{* * *}$ Dept. of Electrical Eng., Korea University, Seoul, Korea
}

\begin{abstract}
Multiphase dc-dc converters are widely used in modern power electronics applications due to their advantages over single-phase converters. Such advantages include reduced current stress in both the switching devices and passive elements, reduced output current ripple, and so on. Although the output current ripple of a converter can be significantly reduced by virtue of the interleaving effect, the inductor current ripple cannot be reduced even with the interleaving PWM method. One way to solve this problem is to use a coupled inductor. However, care must be taken in designing the coupled inductor to maximize its performances. In this paper, a detailed analysis of a coupled inductor is conducted and the effect of a coupled inductor on current ripple reduction is investigated extensively. From this analysis, a UU core based coupled inductor structure is proposed to maximize the performance of the coupled inductor.
\end{abstract}

Key words: Coupled inductor, Interleaved PWM, Multiphase converter, Transformer

\section{INTRODUCTION}

Single-phase dc-dc converters, such as the one shown in Fig. 1 , have some limitations in high current applications due to the excessive power loss caused by the $i^{2} R$ loss in the inductor and the high inductor ripple current. In order to handle these problems, multiphase dc-dc converters, such as the one shown in Fig. 2, have been introduced and widely used in applications such as voltage regulator modules (VRM), power supplies for server applications, and so on. Fig. 3 shows output the current ripple $\left(\Delta i_{L_{o}}\right)$ of a two-phase interleaved buck converter normalized with respect to that of its single-phase counterpart and the well known equation is expressed in (1) [1], [4].

$$
\frac{\Delta i_{L_{o . \text { two-phase }}}}{\Delta i_{L_{\text {o. } \text {.ingle-phase }}}}= \begin{cases}\frac{1-2 D}{1-D}, & D<0.5 \\ \frac{2 D-1}{D}, & D>0.5\end{cases}
$$

Manuscript received Sep. 4, 2012; revised Feb. 21, 2013

Recommended for publication by Associate Editor Se-Kyo Chung.

${ }^{\dagger}$ Corresponding Author: chahonny@knu.ac.kr

Tel: +82-53-950-8972, Fax: +82-53-950-8979, Kyungpook Nat'l Univ.

*Power Conversion \& Control Research Center, KERI, Korea

${ }^{* *}$ Dept. of Electrical Eng., Pusan National University, Korea

**** Dept. of Electrical Eng., Korea University, Korea

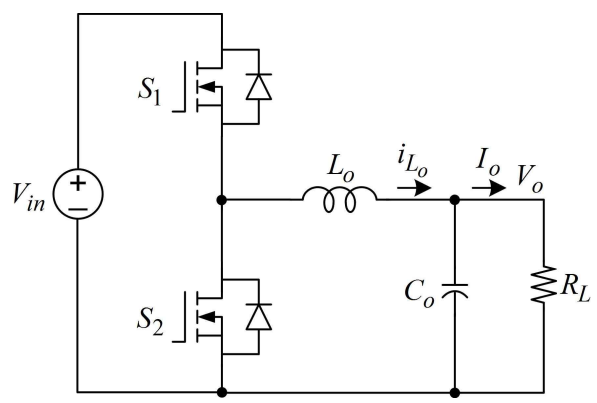

Fig. 1. Single-phase buck converter.

In (1), $D$ is duty cycle of the converter.

From Fig. 3, it can be seen that when compared with the single-phase case, the two-phase interleaved buck converter can reduce the output current ripple significantly. As the number of phases interleaved increases, a lot less output current ripple can be achieved [1], [4]. Conversely, to keep the same output current ripple as the single-phase converter, the inductances $L_{1}$ and $L_{2}$ can be reduced. A reduced inductance is especially important during a load transient because the dc-dc converter can respond quickly [1]-[3]. However, the penalty is an increased inductor current ripple. 


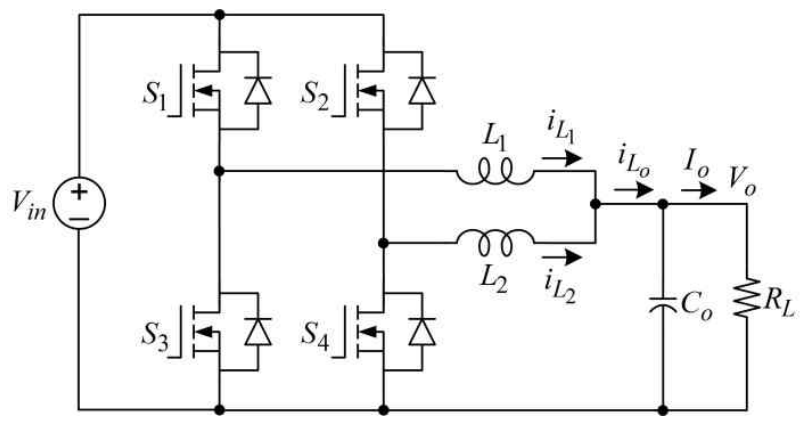

Fig. 2. Two-phase interleaved buck converter.

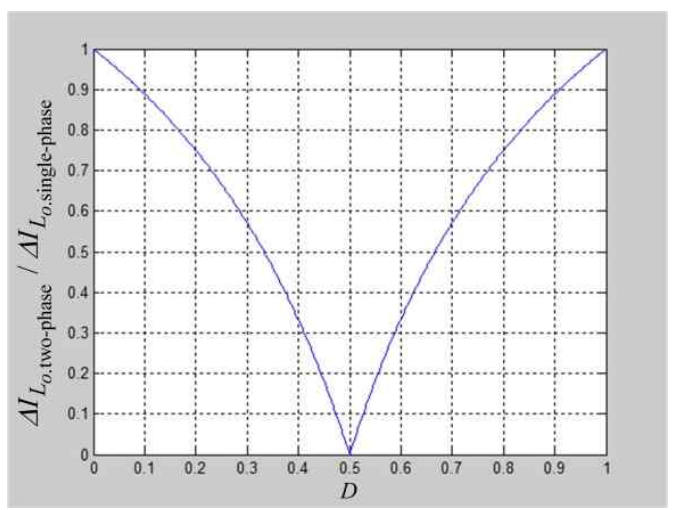

Fig. 3. Output current ripple of two-phase interleaved buck converter normalized with respect to that of single-phase case.

A large inductor current ripple decreases converter efficiency. In order to reduce the inductor current ripple as well as the output current ripple of Fig. 2, the two inductors should be coupled in some way. To date a lot of research efforts have been conducted on interleaved dc-dc converters using a coupled inductor [1]-[13].

In [4], a generalized steady-state analysis of the multi-phase interleaved boost converter was addressed. Detailed coupled inductor modeling and small-signal modeling of a power converter using a coupled inductor were proposed in [1] and [2], respectively. A new modeling approach for analyzing coupled inductors was proposed and a novel canonical symmetrical circuit model was developed in [3]. Similar coupled inductor concepts have been extended to interleaved PWM inverter switching [14], [15].

From a survey of previous literature, it can be seen that the coupling coefficient $(\mathrm{k})$ of the coupled inductor needs to be maximized in order to have optimal performance of the coupled inductor and the power converter. However, there has not been much extensive research on achieving a high $\mathrm{k}$ for coupled inductors. In this paper, a new core structure has been introduced to that end. A UU core based coupled inductor is selected for the coupled inductor design and its unique characteristics are determined.

\section{CURRENT RIPPLE REDUCTION EFFECT OF COUPLED INDUCTORS}

TABLE I

OPERATION MODES OF TWO-PHASE INTERLEAVED BUCK CONVERTER (NON-COUPLED CASE)

\begin{tabular}{|c|c|c|c|c|}
\hline & Mode 1 & Mode 2 & Mode 3 & Mode 4 \\
\hline$v_{L_{1}}$ & $V_{\text {in }}-V_{o}$ & $-V_{o}$ & $-V_{o}$ & $-V_{o}$ \\
\hline$v_{L_{2}}$ & $-V_{o}$ & $-V_{o}$ & $V_{\text {in }}-V_{o}$ & $-V_{o}$ \\
\hline$\frac{d}{d t} i_{L_{1}}$ & increasing & decreasing & decreasing & decreasing \\
\hline$\frac{d}{d t} i_{L_{2}}$ & decreasing & decreasing & increasing & decreasing \\
\hline$\frac{d}{d t} i_{L_{o}}$ & increasing & decreasing & increasing & decreasing \\
\hline
\end{tabular}

In this section, the effect of a coupled inductor on ripple current reduction is discussed and analyzed in great detail. As mentioned in Section I, interleaved dc-dc converters are good in reducing output current ripple. However, the inductor current ripple is not reduced even with the interleaved PWM method unless the inductors are coupled. In this section, the inductor current ripple of both the non-coupled and coupled inductors in two-phase interleaved buck converters are analyzed and compared. The two main issues of interest in the interleaved converter are the inductor (or phase) current ripple and the output current ripple which is sum of the two inductor currents. To compare the ripple reduction effect, the current ripple in a non-coupled inductor is first analyzed.

\section{A. Two-Phase Non-Coupled Inductors}

Fig. 4 shows a two-phase buck converter using a non-coupled inductor. Fig. 5 shows the voltage and current waveforms of $L_{1}$ and $L_{2}$. As can be seen, there are four operating modes. Detailed voltage and current directions in each mode are summarized in Table I.

Since the two inductors are non-coupled, there is no interaction between them, and the inductor current ripple is simply calculated as

$$
\begin{aligned}
& \Delta i_{L_{1}}=\frac{V_{o}}{L_{1}}(1-D) T_{s} \\
& \Delta i_{L_{2}}=\frac{V_{o}}{L_{2}}(1-D) T_{s}
\end{aligned}
$$

If $L_{1}=L_{2}=L$, then inductor current ripple of the non-coupled case is expressed as

$$
\Delta i_{L}=\frac{V_{o}}{L}(1-D) T_{S}
$$

,where $T_{S}$ is switching period of the converter.

On the other hand, since the output current is the sum of $i_{L_{1}}$ and $i_{L_{2}}$, the output current is increasing in mode 1 and decreasing in mode 2 . This cycle repeats again in mode 3 and 4. As a result, the output current ripple occurs twice during a given period $T_{S}$ [6-7], [11]. The equation for the output 


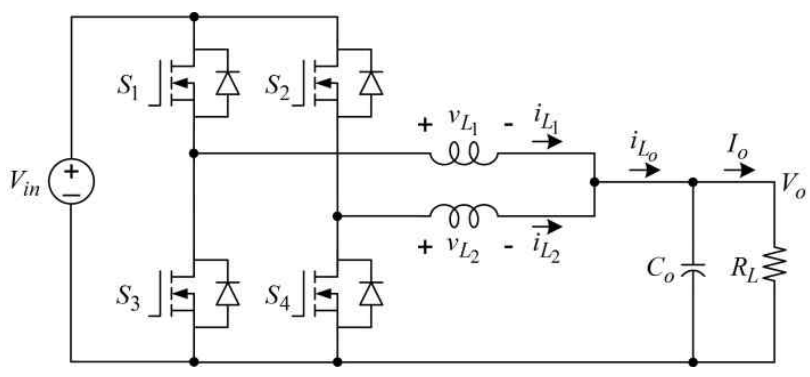

Fig. 4. Two-phase interleaved buck converter (Non-coupled).

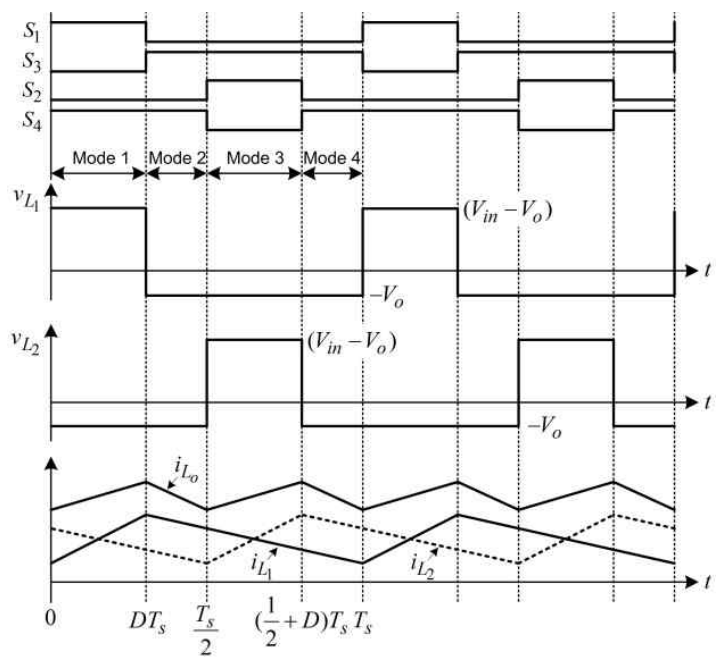

Fig. 5. Key waveforms of two-phase interleaved buck converter (Non-coupled, $\mathrm{D}<0.5$ ).

current ripple is

$$
\Delta i_{L_{O}}=\frac{V_{O}}{L}(1-2 D) T_{S}
$$

To find the ripple current reduction effect of the two-phase interleaved converter, the inductor and output current ripples of the two-phase interleaved converter are compared with its single-phase counterpart. The results are summarized in Table II. Comparing the single-phase and non-coupled two-phase converters, it can be seen that the output current ripple is reduced significantly with the two-phase case and it has its maximum effect when $D$ approaches 0.5 . This can also be verified by the graph shown in Fig. 3. However, it should be noted that the inductor current ripples remain unchanged.

TABLE II

COMPARISON OF CURRENT RIPPLE

\begin{tabular}{|c|c|c|}
\hline & Single-phase & Two-phase (non-coupled) \\
\hline $\begin{array}{c}\text { Inductor } \\
\text { current ripple }\end{array}$ & $\frac{V_{O}}{L}(1-D) T_{S}$ & $\frac{V_{O}}{L}(1-D) T_{S}$ \\
\hline $\begin{array}{c}\text { Output } \\
\text { current ripple }\end{array}$ & $\frac{V_{O}}{L}(1-D) T_{S}$ & $\frac{V_{O}}{L}(1-2 D) T_{S}$ \\
\hline
\end{tabular}

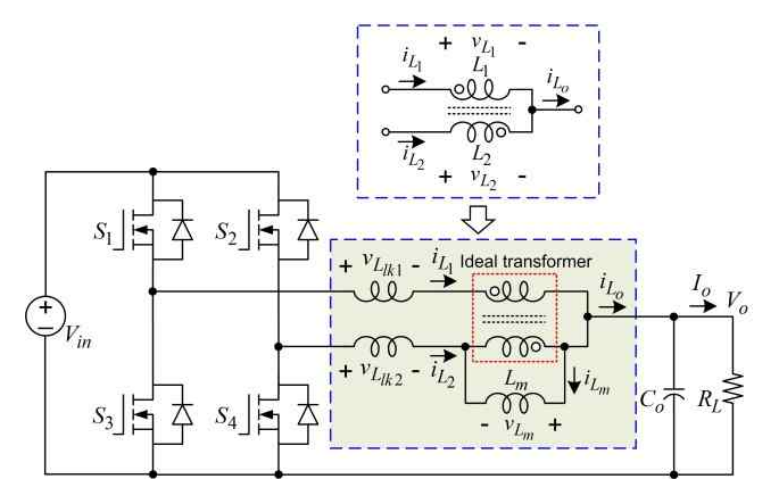

Fig. 6. Two-phase interleaved buck converter (Coupled).

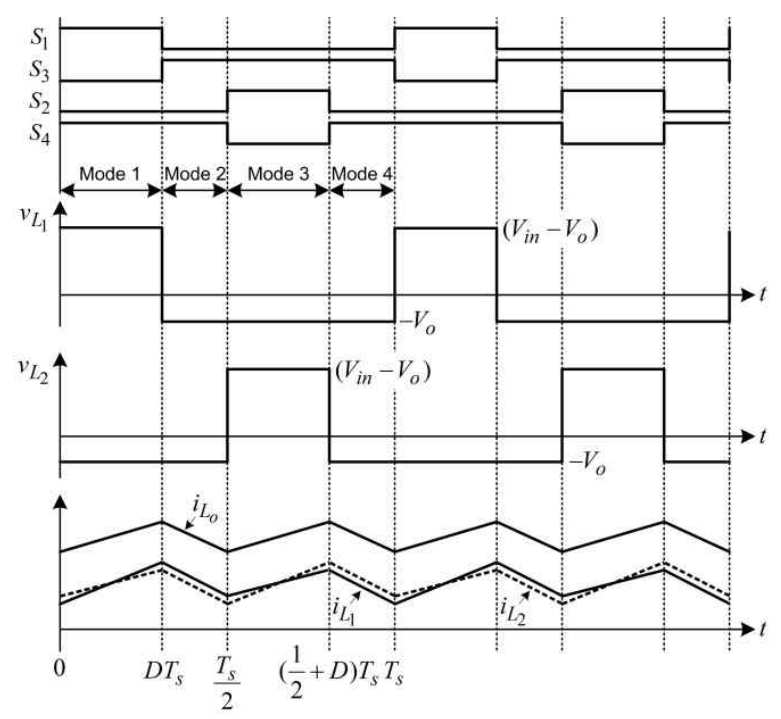

Fig. 7. Key waveforms of two-phase interleaved buck converter (Coupled, $\mathrm{D}<0.5$ ).

\section{B. Two-Phase Coupled Inductors}

Fig. 6 shows a two-phase interleaved buck converter using a coupled inductor. The coupled inductor is represented as an ideal 1:1 transformer, two leakage inductances $\left(L_{l k 1}, L_{l k 2}\right)$, and a magnetizing inductance $\left(L_{m}\right)$. It should be noted that the ideal transformer is connected out of phase with the polarity dots on opposite ends [1]. Therefore,

$$
i_{L_{m}}=i_{L_{1}}-i_{L_{2}}
$$

As in the non-coupled case, there are 4 operation modes in the coupled case. From Fig. 6, it can be seen that the following relationships always apply regardless of the operation mode.

$$
\begin{gathered}
v_{L_{1}}=v_{L_{l k 1}}+v_{L_{m}} \\
v_{L_{2}}=v_{L_{l k 2}}-v_{L_{m}} \\
v_{L_{m}}=L_{m} \frac{d}{d t} i_{L_{m}}=L_{m} \frac{d}{d t}\left(i_{L_{1}}-i_{L_{2}}\right)
\end{gathered}
$$

a) Mode $1\left[0 \sim D T_{s}\right]$ 
From Fig. 6 and Table I, following equations are applied in mode 1.

$$
v_{L_{1}}=V_{\text {in }}-V_{o}, v_{L_{2}}=-V_{o}
$$

From (7), (8) and (10), $v_{L_{l k 1}}$ and $v_{L_{l k 2}}$ are expressed as

$$
\begin{gathered}
v_{L_{l k 1}}=L_{l k 1} \frac{d i_{L_{1}}}{d t}=v_{L_{1}}-v_{L_{m}}=\left(V_{i n}-V_{o}\right)-v_{L_{m}} \\
v_{L_{l k 2}}=L_{l k 2} \frac{d i_{L_{2}}}{d t}=v_{L_{2}}+v_{L_{m}}=\left(-V_{o}\right)+v_{L_{m}}
\end{gathered}
$$

By assuming that $L_{l k 1}=L_{l k 2}=L_{l k}$, and substitute (11)-(12) into (9), then the equation for magnetizing inductance is

$$
v_{L_{m}}=\left(\frac{L_{m}}{2 L_{m}+L_{l k}}\right) V_{i n}
$$

From the general coupled inductor theory, $L_{l k}$ and $L_{m}$ are expressed as [16]

$$
\begin{gathered}
L_{l k}=(1-k) L_{S} \\
L_{m}=k L_{S}
\end{gathered}
$$

,where $L_{s}$ and $k$ represent self inductance and the coupling coefficient of the coupled inductor, respectively.

By substituting (14) and (15) into (13), the following is obtained:

$$
v_{L_{m}}=\left(\frac{k}{1+k}\right) V_{i n}
$$

By substituting (16) back into (11), (12) and using $V_{o}=D V_{\text {in }}$, the inductor currents in mode 1 are

$$
\begin{aligned}
& \frac{d i_{L_{1}}}{d t}=\frac{V_{o}}{L_{l k}}\left(\frac{1-D-k D}{(1+k) D}\right) \\
& \frac{d i_{L_{2}}}{d t}=\frac{V_{o}}{L_{l k}}\left(\frac{k-D-k D}{(1+k) D}\right)
\end{aligned}
$$

The coupling coefficient of the coupled inductor is less than 1 in practice and we have assumed that $D<0.5$. Thus it is obvious that $d i_{L_{1}} / d t$ is positive. On the other hand, $d i_{L_{2}} / d t$ becomes positive if $k>D /(1-D)$. Since $k<1$, the current slope of $L_{1}$ is greater than that of $L_{2}$. The output current is sum of the two inductor currents and thus it is expressed as

$$
\frac{d i_{L_{O}}}{d t}=\frac{V_{o}}{L_{l k}}\left(\frac{1-2 D}{D}\right)
$$

b) Mode $2\left[D T_{s} \sim T_{S} / 2\right]$

In mode 2, $v_{L_{1}}=v_{L_{2}}=-V_{o}$, thus

$$
\begin{aligned}
& v_{L_{l k 1}}=L_{l k 1} \frac{d i_{L_{1}}}{d t}=v_{L_{1}}-v_{L_{m}}=-V_{o}-v_{L_{m}} \\
& v_{L_{l k 2}}=L_{l k 2} \frac{d i_{L_{2}}}{d t}=v_{L_{2}}+v_{L_{m}}=-V_{o}+v_{L_{m}}
\end{aligned}
$$

Substitute (20) and (21) into (9), then $v_{L_{m}}=0$. Thus from (20) and (21), the inductor currents in mode 2 are

$$
\frac{d i_{L_{1}}}{d t}=\frac{d i_{L_{2}}}{d t}=-\frac{V_{o}}{L_{l k}}
$$

The output current ripple is expressed as

$$
\frac{d i_{L_{o}}}{d t}=-\frac{V_{o}}{L_{l k}}\left(\frac{1-2 D}{0.5-D}\right)
$$

c) Mode $3\left[T_{S} / 2 \sim\left(T_{S} / 2+D T_{S}\right)\right]$

Mode 3 is similar to mode 1 . The only difference is that $v_{L_{1}}=-V_{o}$ and $v_{L_{2}}=V_{i n}-V_{o}$. Using a similar methods as that used in mode 1 , the inductor and output current ripple in mode 3 are derived as follows

$$
\begin{aligned}
& \frac{d i_{L_{1}}}{d t}=\frac{V_{o}}{L_{l k}}\left(\frac{k-D-k D}{(1+k) D}\right) \\
& \frac{d i_{L_{2}}}{d t}=\frac{V_{o}}{L_{l k}}\left(\frac{1-D-k D}{(1+k) D}\right)
\end{aligned}
$$

As in mode $1, k<1$ and $D<0.5$. Thus $d i_{L_{2}} / d t$ is positive and $d i_{L_{1}} / d t$ becomes positive if $k>D /(1-D)$. Since $k<1$, the current slope of $L_{2}$ is greater than that of $L_{1}$ in this mode. The output current in mode 3 is same as that of mode 1.

d) Mode $4\left[\left(T_{s} / 2+D T_{s}\right) \sim T_{s}\right]$

Mode 4 is exactly same as mode 2 because $v_{L_{1}}=v_{L_{2}}=-V_{o}$. In (17) and (19), $d t$ is equal to $D T_{s}$ in mode 1 . Therefore, the inductor and output current ripple are expressed as

$$
\begin{gathered}
\Delta i_{L}=\frac{V_{o}}{L_{l k}}\left(\frac{1-D-k D}{1+k}\right) T_{s} \\
\Delta i_{L_{O}}=\frac{V_{o}}{L_{l k}}(1-2 D) T_{s}
\end{gathered}
$$

In (27), it can be seen that the coupling coefficient $k$ does not affect the output current ripple [11]. From (5) and (27), it can be seen that if $L_{l k}$ is equal to the value of the individual inductor $L$ in the non-coupled case, the output current ripple in both the non-coupled and coupled inductor are the same.

From the mode analysis of the coupled inductor, it can be seen that the inductor current ripple depends on the values of $D$ and $k$. Unlike the non-coupled case, the inductor current ripples of the coupled inductor change direction twice per cycle as the output current ripple. As $k$ increased to 1 (perfect coupling), the two inductor currents become equal and in-phase. Thus the coupling coefficient $k$ has a significant effect on the inductor current ripples although it does not affect the output current ripple. Fig. 7 shows the 


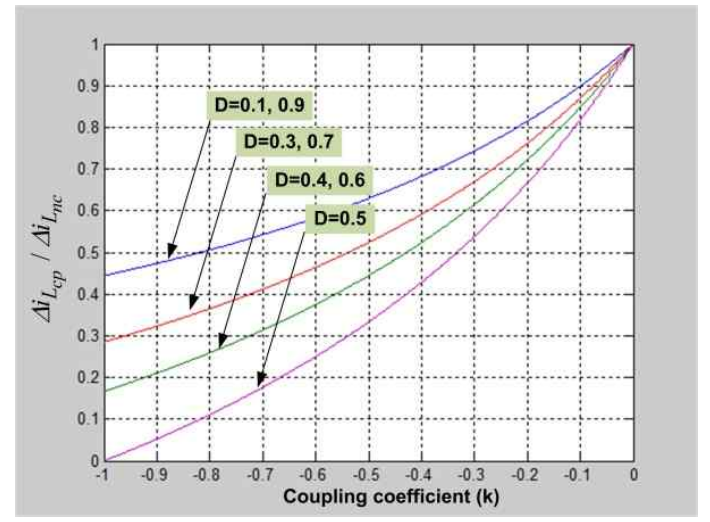

Fig. 8. Inductor current ripple of coupled inductor normalized with respect to the non-coupled case.

theoretical waveforms of the two-phase interleaved buck converter using the coupled inductor.

From (4) and (26), the ratio of inductor current ripple in both the coupled and non-coupled inductor are expressed as

$$
\frac{\Delta i_{L(\text { coupled })}}{\Delta i_{L(\text { non-coupled })}}=\frac{1-\frac{D}{1-D} k}{1+k}
$$

The relationship in (28) is plotted in Fig. 8. As shown in Fig. 8, a smaller current ripple can be achieved with strong coupling coefficient. Fig. 9 shows the simulated inductor and the output current waveforms of the coupled inductor when $k$ varies and they are compared with those of the non-coupled inductor. As mentioned before, if $L_{l k}$ of the coupled inductor is equal to the value of the non-coupled individual inductor $L$ in the non-coupled case, the output current ripples are same. In this simulation, $L_{l k}$ and $L$ are both set to $200 \mu H$ to have the same output current ripple. As expected, the output current ripple does not change as $k$ varies. However, the inductor current ripples change significantly as $k$ varies and have almost same shape as $k$ approaches to 1 . Mode analysis when $D>0.5$ can be conducted in a similar way as when $D<0.5$ and the results are exactly same [1].

\section{PROPOSED COUPLED INDUCTOR STRUCTURE AND ITS OPERATION}

As mentioned in section II, the inductor current ripple is strongly dependent on the coupling coefficient $k$ of the coupled inductor. In order to have the maximum inductor current ripple reduction, the coupled inductor should have high $k$ and also have enough leakage inductance to reduce output current ripple, simultaneously. Fig. 10 shows several existing coupled inductor structures [6], [7]. In order to have the maximum inductor current ripple reduction, center gap structure shown in Fig. 10(c) is preferred because this structure can have the highest $k$. However, this structure has

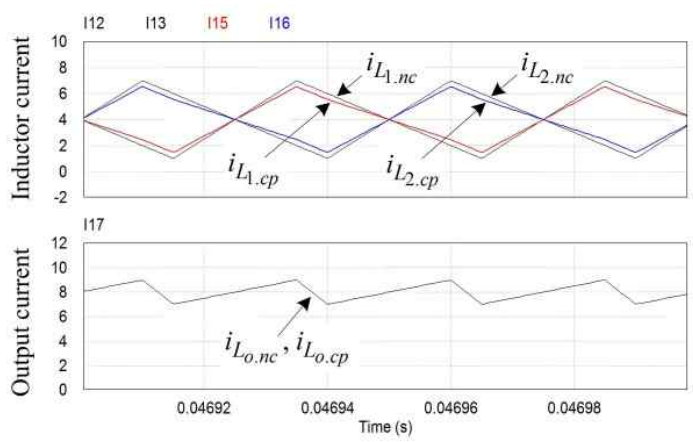

(a) $k=0.1$

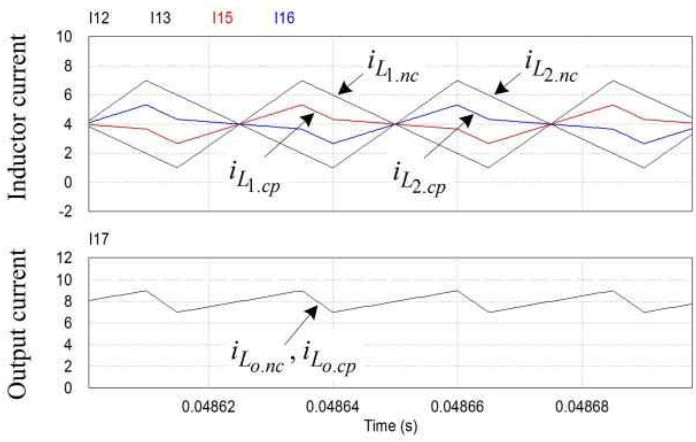

(b) $k=0.5$
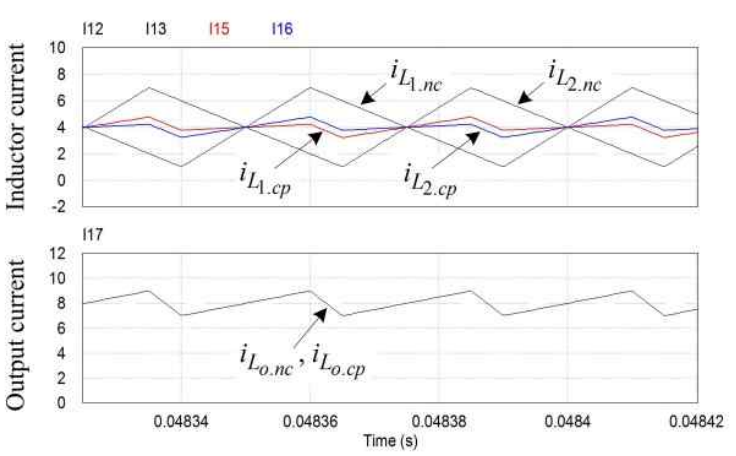

(c) $k=0.8$.
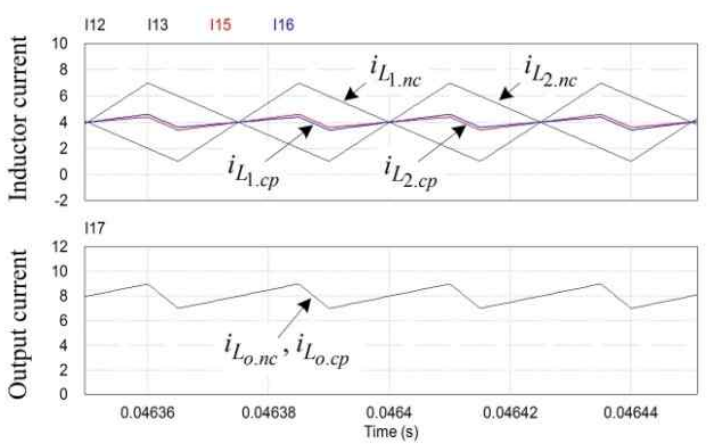

(d) $k=0.95$.

Fig. 9. Simulated inductor and output current waveforms when $k$ varies $(\mathrm{Vin}=100 \mathrm{~V}, \mathrm{D}=0.4)$. 


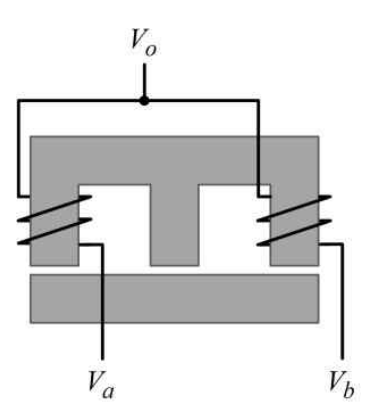

(a) all gaps (moderate $\mathrm{k}$ ).

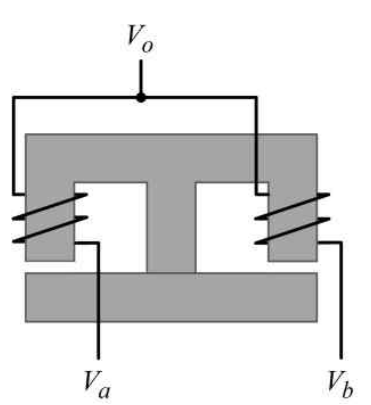

(b) outer gaps (weak k).

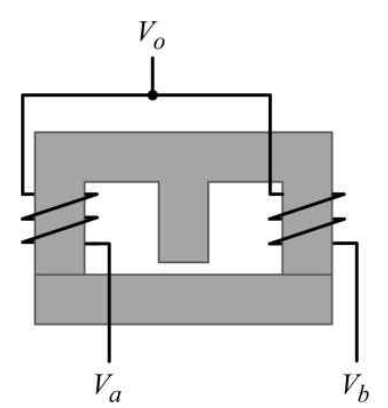

(c) center gap (strong $\mathrm{k}$ ).

Fig. 10. Several gapping configuration for two-phase coupled inductor.

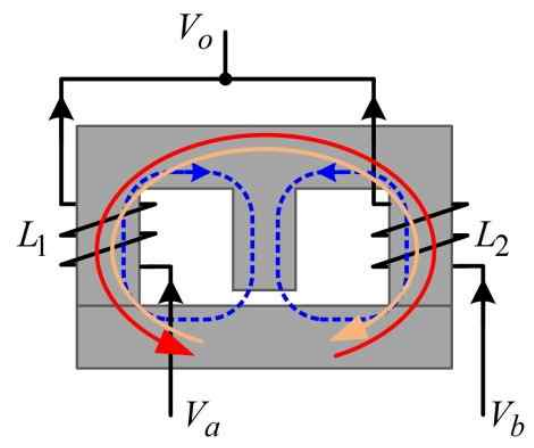

Fig. 11. Flux distribution and path of the coupled inductor.

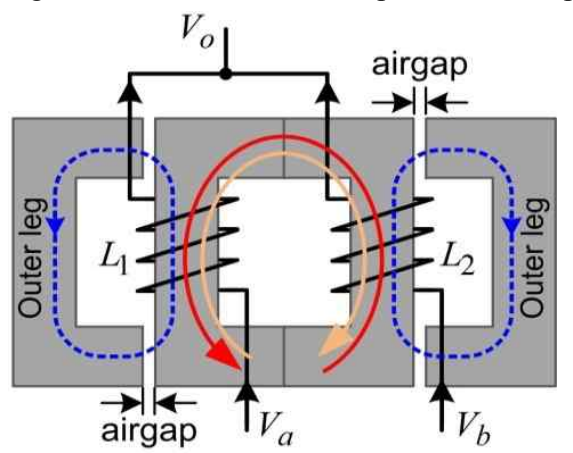

Fig. 12. Proposed coupled inductor structure.

some difficulties in adjusting the airgap (or inductance) because the center leg should be cut off or grinded out to obtain the wanted airgap. Once the core is cut, only one inductance value can be obtained. This may reduce the flexibility of the core. In addition, it is not mechanically stable if they are used for high power applications. Fig. 11 shows the flux distribution of the coupled inductor of Fig. 10(c). The solid and dotted lines represent the coupling and the leakage flux, respectively.

In order to overcome the aforementioned limitations, a UU core structure, as in Fig. 12, is proposed in this paper. As shown in Fig. 12, the core has four legs. The two inner legs have winding on them and no winding on the other two outer legs. The two inner legs provide the coupling path for the fluxes generated by the windings and thus there is no airgap in this path. However, the two outer legs provide the path for the leakage flux and thus an airgap is required to store energy. Without that leg, the leakage flux will flow through the air

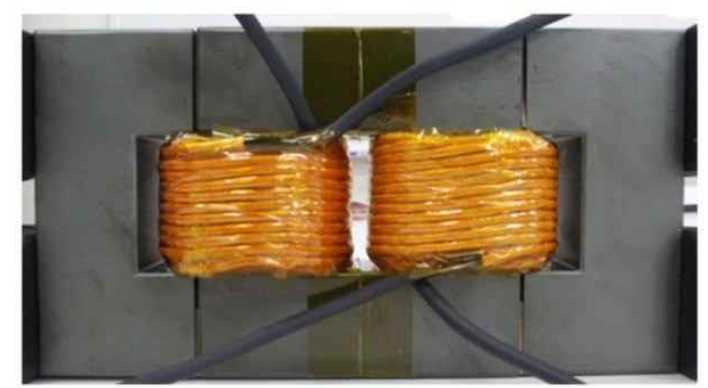

Fig. 13. Prototype coupled inductor picture.

path between the top and bottom cores and there will not be enough inductance. An added benefit of outer leg is that it will prevent a possible induction heating problem caused by the leakage flux when there is metal around the outer legs. This is especially so in high power applications. Similar to Fig. 11, the solid line represents the coupling flux and the dotted line represents the leakage flux in the core. The proposed core structure can easily adjust the airgap and it is mechanically more stable than Fig. 11.

\section{EXPERIMENTAL RESULTS}

A prototype coupled inductor was built and tested to verify performances of the coupled inductor. Fig. 13 shows the picture of the prototype coupled inductor built in this paper. Table III shows electrical specifications of the proposed converter. As shown, the proposed coupled inductor has a very high $k$.

In the test, two test setups, as shown in Fig. 14, are used to compare the inductor and the output current ripples of the converter. As in Fig. 14, the two inductors are just separated in (a) and coupled in (b). No extra winding or core is used in the comparison. The measured inductance of the non-coupled inductor is $220 \mu \mathrm{H}$.

Fig. 15 shows the experimental waveforms of the inductor and the output current when $\mathrm{D}=0.2$. As expected, the output current ripple is same in both cases because $L_{l k}=L$. However, the inductor current in coupled inductor has small current ripple than non-coupled inductor and the two inductor currents are almost in phase. 


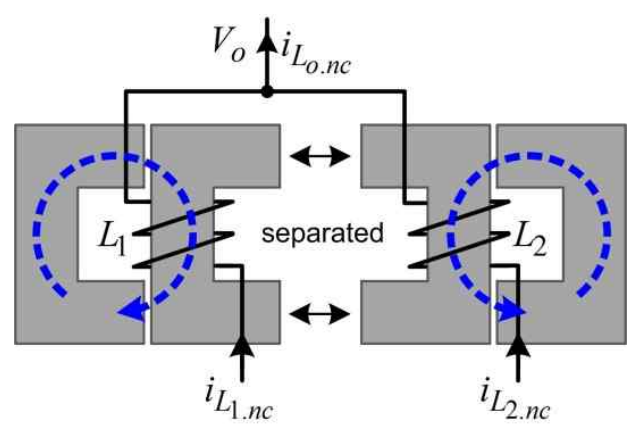

(a) Non coupled.

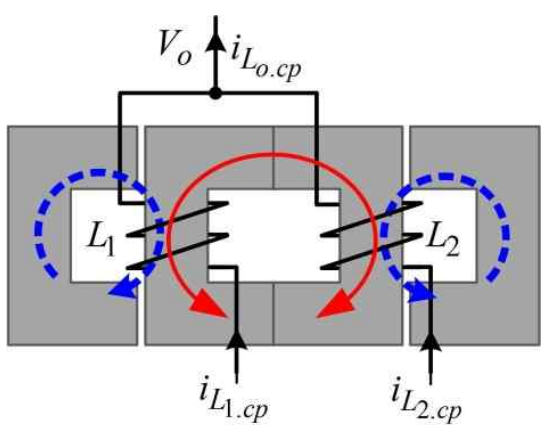

(b) Coupled.

Fig. 14. Test setup.

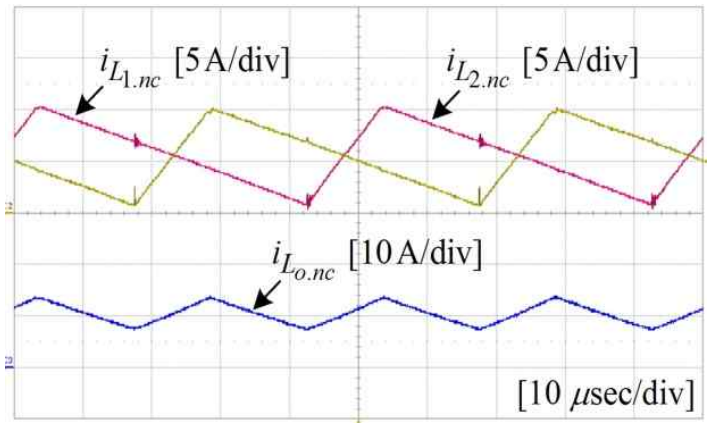

(a) Non-coupled inductor.

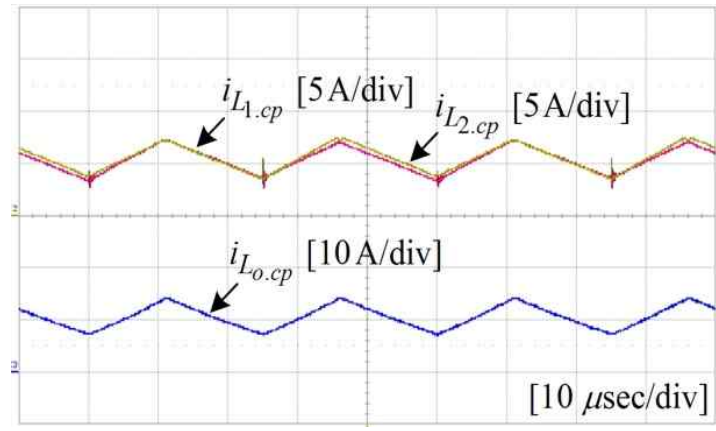

(b) Coupled inductor.

Fig. 15. Experimental results when $V_{\text {in }}=300 \mathrm{~V}, D=0.2$ and $R_{L}=6 \Omega$.

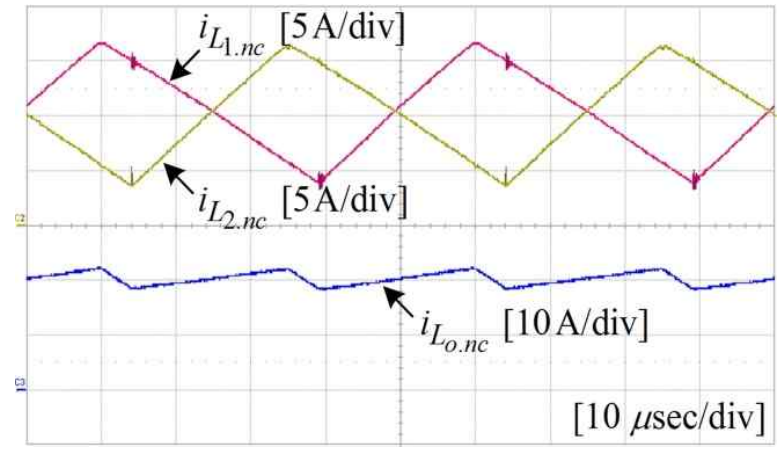

(a) Non-coupled inductor.

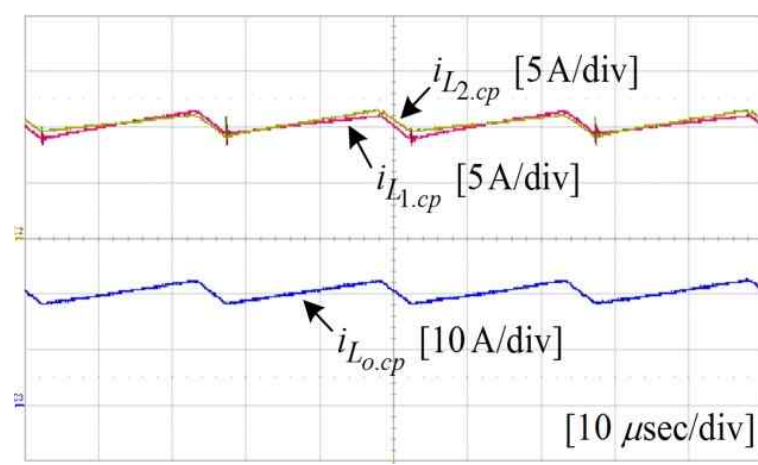

(b) Coupled inductor.

Fig. 16. Experimental results when $V_{\text {in }}=300 \mathrm{~V}, D=0.4$ and $R_{L}=6 \Omega$.

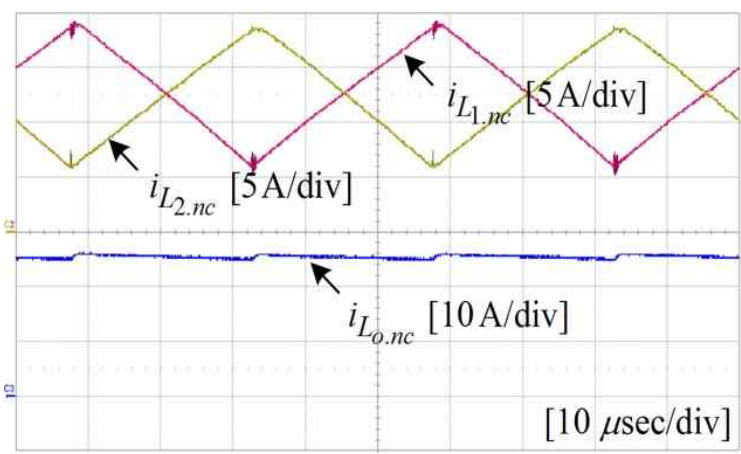

(a) Non-coupled inductor.

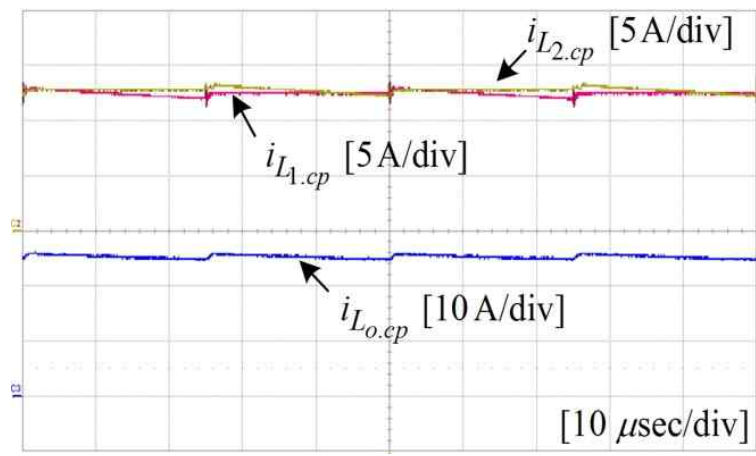

(b) Coupled inductor.

Fig. 17. Experimental results when $V_{i n}=300 \mathrm{~V}, D=0.5$ and $R_{L}=6 \Omega$. 
TABLE III

Electrical SpecificAtions of THE Proposed CONVERTER

\begin{tabular}{|c|c|c|}
\hline \multicolumn{2}{|c|}{ INPUT VOLTAGE } & $300 \mathrm{~V}$ \\
\hline \multicolumn{2}{|c|}{ SWITCHING FREQUENCY } & $20 \mathrm{kHz}$ \\
\hline \multirow{7}{*}{$\begin{array}{l}\text { COUPLED } \\
\text { INDUCTOR }\end{array}$} & CORE USED & FERRITE CORE (UU-95) \\
\hline & NO. OF TURNS & 21 TURNS \\
\hline & $\begin{array}{l}\text { SELF INDUCTANCE } \\
\left(L_{S}\right) \text { MEASURED }\end{array}$ & $2.933 \mathrm{mH}$ \\
\hline & $\begin{array}{c}\text { MAGNETIZING } \\
\text { INDUCTANCE }\left(L_{m}\right)\end{array}$ & $2.72 \mathrm{mH}$ \\
\hline & MEASURED & \\
\hline & $\begin{array}{c}\text { LEAKAGE } \\
\text { INDUCTANCE }\left(L_{l k}\right) \\
\text { MEASURED }\end{array}$ & $213 \mu H$ \\
\hline & $\begin{array}{c}\text { COUPLING } \\
\text { COEFFICIENT }(k)\end{array}$ & $\frac{2.72 m H}{2.933 m H}=0.927$ \\
\hline
\end{tabular}

Fig. 16 and 17 show the same current waveforms as Fig. 15 when $\mathrm{D}=0.4$ and 0.5 , respectively. The output current ripples are still the same in both the non-coupled and the coupled cases. As D gets closer to 0.5, the output current ripple decreases gradually and becomes the minimum at $\mathrm{D}=0.5$ due to the interleaving effect. This effect is also shown in Fig. 3.

Although the output current ripple is the minimum at $\mathrm{D}=0.5$, the inductor current ripple in the non-coupled inductor becomes the maximum at this duty cycle because the maximum flux (or volt-sec) is applied to the inductor when $\mathrm{D}=0.5$. Unlike the non-coupled case, the inductor current ripple in the coupled inductor becomes the minimum at this duty cycle because of the coupling effect. Therefore, both the inductor and the output current ripple becomes the minimum (ideally zero) at $\mathrm{D}=0.5$. This is very interesting result and shows the beauty of the coupled inductor in an interleaved buck converter. If a dc-dc converter is always operating at around $\mathrm{D}=0.5$, the coupled inductor can be extremely small.

Fig. 18 compares the measured efficiency of the converter when the output power varies from $500 \mathrm{~W}$ to $4 \mathrm{~kW}$ while $\mathrm{Vin}=300 \mathrm{~V}$ and $\mathrm{D}=0.5$. Fig. 19 shows the measured inductor temperature variation during the 2 hour inductor test. From the results of Fig. 18 and 19, it is evident that the coupled inductor has less of a temperature increase (or less power loss) than non-coupled inductor. Due to this, the efficiency of the converter can be improved significantly with the coupled inductor especially under light and intermediate loads.

\section{CONCLUSIONS}

In this paper, the effect of a coupled inductor on both the inductor and the output current ripple is studied in great detail. From the analysis, it was shown that the coupling coefficient should be high enough to effectively reduce the inductor current ripple. It was also shown that enough leakage

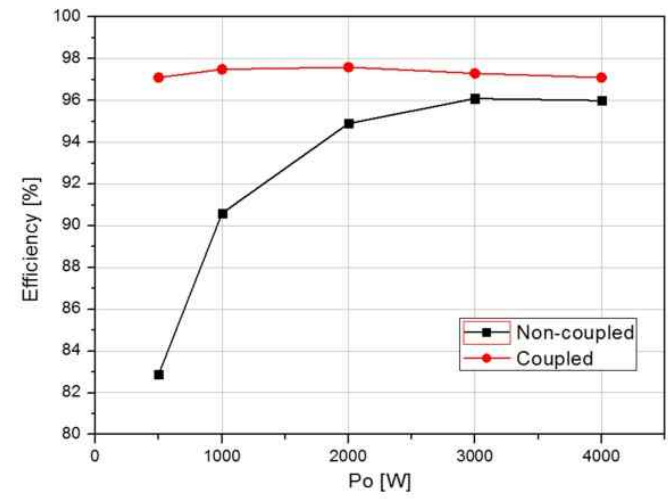

Fig. 18. Measured efficiency ( $V_{\text {in }}=300 \mathrm{~V}, D=0.5$ ).

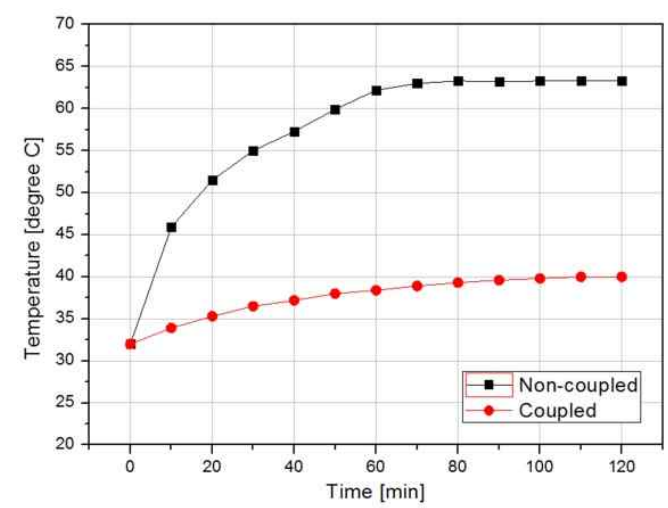

Fig. 19. Measured inductor temperature $\left(V_{\text {in }}=300 \mathrm{~V}, D=0.5\right.$, and $\left.P_{o}=4 \mathrm{~kW}\right)$.

inductance is required to minimize the output current ripple of the converter. In order to meet both of the requirements of the coupled inductor, a UU-core based coupled inductor structure was proposed. A two-phase interleaved buck converter using the proposed coupled inductor is built and successfully tested to verify performances of the coupled inductor.

\section{ACKNOWLEDGMENT}

This research was partly supported by Kyungpook National University Research Fund, 2012 and partly supported by Basic Science Research Program through the National Research Foundation of Korea(NRF) funded by the Ministry of Education, Science and Technology(2012R1A1A1044058)

\section{REFERENCES}

[1] W. Pit-Leong, X. Peng, P. Yang, and F. C. Lee, "Performance improvements of interleaving VRMs with coupling inductors," IEEE Trans. Power Electron., Vol. 16, No. 4, pp. 499-507, Jul. 2001.

[2] M. Xu, J. Zhou, K. Yao, and F. C. Lee, "Small signal modeling of a high bandwidth voltage regulator using 
coupled inductors," IEEE Trans. Power Electron., Vol. 22, No. 2, pp. 399-406, Mar. 2007.

[3] G. Zhu, B. McDonald, and K. Wang, "Modeling and analysis of coupled inductors in power converters," IEEE Trans. Power Electron., Vol. 26, No. 5, pp. 1355-1363, May 2011

[4] H. B. Shin, J. G. Park, S. K. Chung, H. W. Lee, and T. A. Lipo, "Generalised steady-state analysis of multiphase interleaved boost converter with coupled inductors," Electric Power Applications, IEE Proceedings, Vol. 152, pp. 584-594, 2005.

[5] P. Wong, "Performance Improvement Of Multi-Channel Interleaving Voltage Regulator Modules With Integrated Coupling Inductors," Ph.D. dissertation, Dept. Electr. Comput. Eng., Virginia Tech, Blacksburg, Mar. 2001.

[6] L. Jieli, C. R. Sullivan, and A. Schultz, "Coupled-inductor design optimization for fast-response low-voltage dc-dc converters," in Proc. IEEE APEC, pp. 817-823, 2002.

[7] L. Jieli, A. Stratakos, A. Schultz, and C. R. Sullivan, "Using coupled inductors to enhance transient performance of multi-phase buck converters," in Proc. IEEE APEC, pp. 1289-1293, 2004.

[8] S. Chandrasekaran and L. U. Gokdere, "Integrated Magnetics for Interleaved DC-DC Boost Converter for Fuel Cell Powered Vehicles," in Proc. PESC, pp.356-361, 2004.

[9] P. Zumel, O. Garcia, J. A. Cobos, and J. Uceda, "Magnetic integration for interleaved converters," in Proc. IEEE APEC, pp. 1143-1149, 2003.

[10] L. Yim-Shu, W. Leung-Pong, and D. K. W. Cheng, "Simulation and design of integrated magnetics for power converters," IEEE Trans. Magn., Vol. 39, No. 2, pp. 1008-1018, Mar. 2003.

[11] J. Gallagher, "Coupled inductors improve multiphase buck efficiency," Power Electron. Technol. Mag., pp. 36-42, Jan. 2006.

[12] S. Xiao, W. Qui, T. Wu, and I. Batarseh, "Investigating effects of magnetizing inductance on coupled-inductor voltage regulators," in Proc. IEEE APEC, pp. 1569-1574, 2008.

[13] F. Yang, X. Ruan, Y. Yang, and Z. Ye, "Interleaved critical current mode boost PFC converter with coupled inductor," IEEE Trans. Power Electron., Vol. 26, No. 9, pp. 2404-2413, Sep. 2011.

[14] A. Knight, J. Ewanchuk, and J. Salmon, "Coupled three-phase inductors for interleaved inverter switching," IEEE Trans. Magn., Vol. 44, No. 11, pp. 4119-4122, Nov. 2008.

[15] J. Salmon, J. Ewanchuk, and A. Knight, "PWM inverters using split-wound coupled inductors," IEEE Trans. Ind. Appl., Vol. 45, No. 6, pp. 2001-2009, Nov./Dec. 2009.

[16] A. F. Witulski, "Introduction to modeling of transformers and coupled inductors," IEEE Trans. Power Electron., Vol. 10, No. 3, pp. 349-357, May 1995.

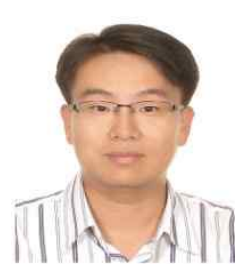

Jong-Pil Lee received his B.S. and M.S. in Control and Instrumentation of Engineering and Electrical Engineering from Korea University, Seoul, Korea, in 1997 and 1999, respectively, and his Ph.D. from the School of Electrical Engineering of Korea University, in 2012. From 1999 to 2005, he was a Senior Researcher at Hyundai Heavy Industries in the Electric and Hybrid Vehicle Research Section. $\mathrm{He}$ has been working as a Senior Researcher in the Power
Conversion and Control Research Center, HVDC Research Division of the Korea Electrotechnology Research Institute (KERI), Changwon, Korea. His current research interests include photovoltaic PCS, PMSG wind turbine PCS, distributed power generation systems, and power conversion for HVDC systems.

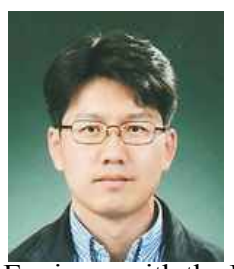

Honnyong Cha received his B.S. and M.S. in Electronics Engineering from Kyungpook National University, Daegu, Korea, in 1999 and 2001, respectively, and his Ph.D. in Electrical Engineering from Michigan State University, East Lansing, Michigan, in 2009. From 2001 to 2003, he was a Research Engineer with the Power System Technology (PSTEK) Company, An-san, Korea. From 2010 to 2011, he worked as a Senior Researcher at the Korea Electrotechnology Research Institute (KERI), Changwon, Korea. In 2011, he joined Kyungpook National University as an Assistant Professor in the School of Energy Engineering. His current research interests include high power dc-dc converters, dc-ac inverters, Z-source inverters, and power conversion for electric vehicles and wind power generation.

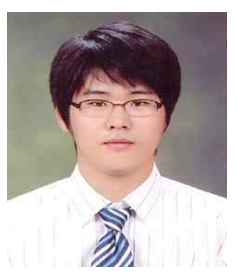

Dongsul Shin received his B.S. and M.S. in Electrical Engineering from Pusan National University, Busan, Korea, in 2009 and 2011, respectively. Currently, he is working towards his Ph.D. in the School of Electrical Engineering, Pusan National University. Since 2010, he has been working as a Researcher in the Power Conversion and Control Research Center, HVDC Research Division of the Korea Electrotechnology Research Institute (KERI), Changwon, Korea. His current research interests include grid-connected inverters, power quality and digital control.

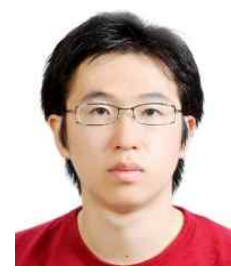

Kyoung-Jun Lee received his B.S. and M.S. in Electrical Engineering from Pusan National University, Busan, Korea, in 2008 and 2010, respectively. Currently, he is working towards his Ph.D. in the School of Electrical Engineering, Pusan National University. His current research interests include power conversion of renewable energy systems, power quality and ac filter design.

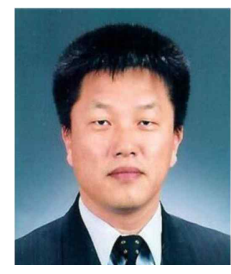

Dong-Wook Yoo received his B.S. in Electrical Engineering from Sungkyunkwan University (SKKU), Suwon, Korea, in 1983, his M.S. in Electrical Engineering from Yonsei University, Seoul, Korea, in 1985, and his $\mathrm{Ph} . \mathrm{D}$. in Power Electronics from SKKU, in 1997. He became a Researcher in 1985, a Senior Researcher in 1989, and a Principal Researcher in 1997 at the Korea Electrotechnology Research Institute (KERI), Changwon, Korea. Since 1997, he has been a Team Leader of the Power Electronics Laboratory and the Renewable Energy Laboratory at KERI. 


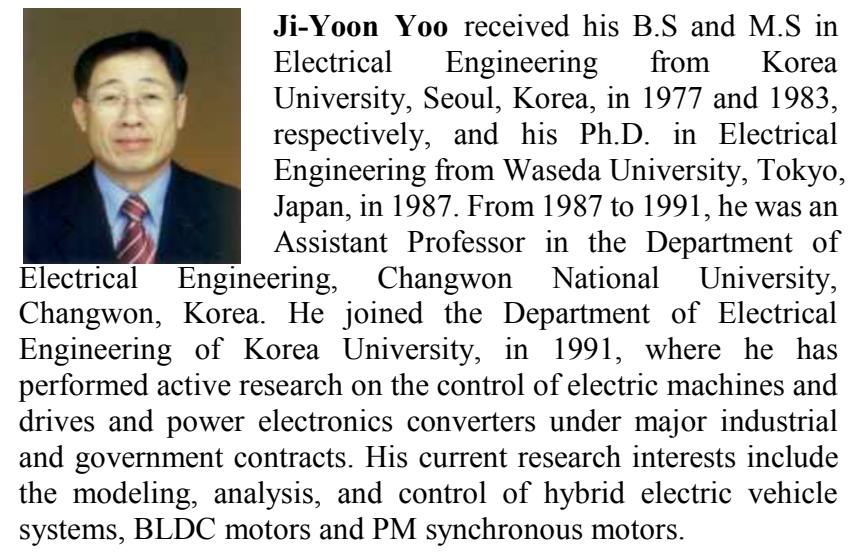

